\title{
Lazos rotos. La inmigración, el matrimonio $y$ las emociones en Argentina entre los siglos XIX y XX
}

\author{
María Bjerg (2019). Bernal, Universidad Nacional de Quilmes, 128 pp.
}

\section{( Julia Bacchiega \\ UNSAM-UdeSA-Conicet}

En Lazos rotos María Bjerg analiza el impacto de la experiencia migratoria transatlántica en los vínculos matrimoniales desde una dimensión emocional, en el período comprendido entre los años ochenta del siglo XIX y la Primera Guerra Mundial. Es un libro de historia pero, a su vez, es un libro de historias de parejas italianas y españolas que, a diferencia de muchas otras, no lograron superar los costos emocionales del proyecto migratorio. Los hechos transcurren en una geografía diversa entre pueblos y ciudades pequeñas de la provincia de Buenos Aires, la capital de la nación y las aldeas de origen en Europa.

Es la confluencia de un tema conocido problematizado desde una nueva mirada lo que sobresale y destaca la originalidad del enfoque. La exhaustiva investigación se encuentra inserta dentro de una tradición historiográfica densa en la Argentina en lo que respecta a los estudios sobre migraciones, pero también en una menos explorada corriente que lleva pocas décadas abordada como objeto de pesquisa autónomo: las emociones. A partir de su uso como dimensión analítica Bjerg dará continuidad en Lazos rotos a sus trabajos sobre migraciones, vínculos familiares, vida cotidiana, parentesco, sociabilidad y conflictos en contextos multiétnicos. La propuesta es novedosa ya que consiste en problematizar la gestión de las emociones de las y los protagonistas de las historias a partir del estudio de las conductas, las prácticas culturales, los estilos emocionales y las disputas desarrolladas a ambos lados del océano Atlántico.

Resulta válido preguntarse cómo puede comprenderse el pasado a través de las emociones teniendo en cuenta que son sentimientos propios vivenciados por cada persona. La autora explica que su interpretación debe ser hecha a partir del conocimiento del contexto en el cual se presentan, ya que en diferentes épocas y sociedades las formas en que se experimentan y se expresan cambian de significado.
En este sentido, resulta particularmente interesante su abordaje de las emociones desde una perspectiva de género que le permite plantear que una misma emoción podía cobrar distintos sentidos según fuera manifestada por un hombre o por una mujer. Por ejemplo, mientras que la ira podía ser admitida como reacción válida por parte de los hombres, en las mujeres se reprobaba argumentando una peligrosidad patológica.

Dado que las emociones no son inmutables, sino que se gestionan, se construyen y se transforman, los interrogantes de Bjerg buscan dar cuenta de la resignificación de las subjetividades de los cónyuges, pues el lazo que unía a las parejas era desafiado por la distancia y el tiempo y un vínculo a priori indisoluble podía romperse cuando las emociones afines al cariño devenían hacia otras contrarias.

Las historias seleccionadas tienen en común el hecho de que sus actores transgredieron la ley argentina y que sus desenlaces fueron poco felices o trágicos. Bjerg recuperó estas tristes realidades, surcadas por el desamor, de expedientes judiciales y las reconstruyó con una fluida y estilizada narrativa interpretando los lenguajes, la expresión y la demostración de las emociones de los cónyuges, pero también de las comunidades étnicas dentro de las cuales giraban sus vidas. Las trayectorias individuales y compartidas fueron rastreadas de forma minuciosa y destacable en un corpus documental que abarca registros civiles, parroquiales, censos y prensa con el fin de complementar la información más allá de la revelada en los expedientes.

Será a través de casos de bigamia, adulterio, lesiones y uxoricidio que Bjerg entrelazará la migración, las relaciones matrimoniales y las emociones insertas en problemas sociales y culturales más amplios. Entre estos sobresalen la conservación del honor de los 
hombres, el control masculino sobre la sexualidad femenina y la rebelión ante prácticas autoritarias por parte de las mujeres.

El libro se compone de una introducción, cuatro capítulos y un breve epílogo. En el capítulo 1 "La promesa, la espera y la traición”, Bjerg describe casos en los que mujeres europeas denunciaron a sus esposos por bígamos. La migración iniciada por los hombres se basaba en un pacto con sus esposas a partir del cual el vínculo se mantenía sobre la base de la promesa del futuro reencuentro y de la espera. Durante el tiempo que estaban separados la relación se mantenía mediante el intercambio de cartas y el envío de remesas de las que dependían la mujer y los hijos para sobrevivir hasta el retorno del cónyuge, o del hecho de ser "mandadas a llamar" con el fin de reunificar la familia en la Argentina. Sin embargo, tanto la regularidad de la correspondencia como la de las remesas podía variar debilitando el vínculo, dado que podían pasar largos años hasta encontrarse. Justificándose en el tiempo y la ruptura de la comunicación, algunos hombres contrajeron matrimonio nuevamente en la Argentina, alegaban en su defensa haber creído que sus mujeres habían fallecido. Esta traición agravada por el hecho de haber sido abandonadas y olvidadas hizo que algunas esposas legítimas llegaran a la Argentina siguiendo el rastro de sus maridos y recurrieran a la justicia. Los casos presentados son diversos, así como los fines con que los litigios se iniciaron, pero en conjunto dan cuenta de las acciones de mujeres desafiantes que, con mayor o menor grado de preparación, se valieron de recursos legales participando, según muestra la autora, de performances emocionales en el "teatro judicial”. A su vez, se logra vislumbrar el control del comportamiento de los y las migrantes por parte de las comunidades emocionales de paisanos y deja en claro que el mantenimiento del honor, ligado a los valores morales sobre la conducta sexual de las mujeres impactaba en la familia entera y, sobre todo, en la honra masculina que podía defenderse y conservarse dentro de un repertorio limitado de acciones. Sin embargo, ante los "viudos de vivas" existían como contraparte las "viudas de vivos" con necesidades sexuales, emocionales y afectivas que prácticas como el adulterio y el concubinato podían satisfacer. Es por ello que en el capítulo 2 "Quebrantar los deberes sagrados" esta vez son los maridos quienes denuncian a sus mujeres por haberlos engañado y abandonado acusándolas por cometer el delito de adulterio. Mientras que de los hombres migrantes se esperaba que cumplieran con su deber de proveedores, de sus mujeres se esperaba sumisión, decoro y castidad. Por este motivo quedaban bajo la supervisión masculina de sus suegros, padres o hermanos. Con su posterior viaje a la Argentina muchas veces las expectativas chocaban contra una realidad que no esperaban. Sus maridos no habían progresado económicamente y se encontraban en un nuevo país, sumidas en similares condiciones de miseria junto a alguien a quien debían obediencia, pero por quien ya no sentían afecto. Ante estas circunstancias algunas mujeres optaron por fugarse y abandonar el hogar marital en compañía de sus amantes, con quienes podían haber establecido previamente una relación en Europa o en la Argentina. Salvador Calabrese dijo ignorar "las razones de la conducta reprochable de su esposa", pero cuando un magistrado le preguntó a Teresa Salomón si era consciente de que había cometido un delito penado por la ley respondió que no sabía que fuera delito "irse de donde le daban miseria y malos tratos". Bjerg plantea que la fuga y el adulterio se presentan como "destellos de libertad", momentos en que las mujeres podían escapar de una vida infeliz, pero como reacción a ese tipo de comportamiento los maridos experimentaban ira, venganza y vergüenza ante la ofensa de su honor. Algunas historias dan cuenta de la formación de una nueva familia por parte de las mujeres y la posterior aparición y denuncia del marido, incluso después de haber pasado años de estar ausente. Aunque las condiciones de vida intolerables habilitaban la rebelión de las mujeres ni siquiera el abandono por parte de sus maridos y su desamparo les concedía indulgencia sobre su conducta insubordinada en una sociedad que las condenaba al identificarlas como "putas" pues, a diferencia de la infidelidad de los hombres, la de las mujeres acarreaba consecuencias difíciles de esconder, como el embarazo y los hijos ilegítimos.

El capítulo 3 aborda el problema de "Cuerpos (in) dóciles y odios cotidianos”. A partir del análisis de causas abiertas por lesiones, Bjerg pone en tensión tanto el macro como el microcosmos social entendiendo que la violencia doméstica, que no era la norma pero que existía en muchos hogares, era una vía de resolución de conflictos y de restablecimiento de equilibrios socialmente valorados como la reputación, la autoridad y el honor. En general, las víctimas del maltrato y del abuso eran las mujeres siendo la ira la emoción predominante que desencadenaba la violencia física. Elvira Venezia fue golpeada por su marido en la cabeza con un hacha luego de ser acusada de serle infiel, mientras que Mariano Darbano golpeó brutalmente a su mujer según dijo "obligado a hacerlo para evitar que la esposa mande más que él en el hogar”. Ante estos casos, la autora observa en "el cuerpo de la mujer, un mapa surcado 
de cicatrices que cartografiaban el territorio de un matrimonio mal avenido". Aunque en menor medida, la violencia de las mujeres hacia sus maridos también existió. Catalina Garozzi "se le adelantó, tomó el arma y le dio cinco disparos en las piernas". Su reacción iracunda fue vista como un defecto de carácter grave y peligroso mientras que el mismo tipo de reacción en los hombres se justificaba. Esto demuestra que una emoción podía tener múltiples interpretaciones y cobrar distintos sentidos según el género de quien las expresara. Es destacable el análisis de los casos a partir de la presentación de los puntos de vista de la víctima, el acusado, el defensor y el juez y que más allá de las diferencias de clase entre los magistrados y los acusados existía un consenso sobre la obediencia que las mujeres debían a sus maridos que orientaba la resolución del fallo a favor de estos últimos. A los valores morales y sexuales patriarcales se le sumaba la legislación civil que, al obligar a la esposa a vivir con el varón y al subordinarla legalmente al marido, la dejaba al margen de la ley. Debido a ello quienes lograban separarse de forma autónoma y mantenerse mediante un empleo asalariado eran acosadas por sus maridos que entendían que esas ganancias les pertenecían. Fue así que el dinero que ganaban se volvió motivo de disputas conyugales que derivaron en nuevos maltratos y hechos de sangre. Como demuestra a continuación la autora la escalada de violencia cotidiana ocasionaba también finales trágicos.

El capítulo 4 analiza "La pasión de los celos" en los casos de uxoricidios, denominación dada a los crímenes en donde los maridos asesinaban a sus esposas. Bjerg contrasta la semántica judicial con la de la prensa policial. Mientras que en esta última se explicaban las razones de la conducta homicida por el amor de los hombres manifestado mediante los celos y la locura, en los expedientes los celos aparecen como el motor de la violencia porque era la infidelidad femenina la que alteraba las facultades mentales del varón, lo que derivaba en "impulsos violentos". La autora da cuenta de las formas en que los conflictos conyugales solían atravesar diversas instancias de resolución en recorridos emocionales con "tramas circulares" que se alternaban entre las esferas pública y privada articulando diferentes emociones cargadas de violencia.

Filomena Mastrostéfano desafió la autoridad y el poder de un marido por el que ya no sentía afecto sino desprecio, rencor y hastío. Ángel Fiorda alegó haberla apuñalado porque "tenía macho". Defensores, fiscales y jueces ubicaron el crimen en la intersección entre la infidelidad, los celos y el cariño. Sin embargo, cuando la autora se pregunta sobre qué clase de crímenes fueron los uxoricidios concluye que lejos de mediar un sentimiento de afecto la emoción predominante fue el odio.

Es posible concluir que Lazos rotos no solo realiza una importante contribución a la historia de las migraciones, sino que se presenta como un libro fundante de un campo historiográfico incipiente en la Argentina. Se convertirá, sin lugar a dudas, en una fuente de consulta indispensable para quienes se sientan atraídos/as por la historia de las emociones. Es destacable, además, el meticuloso seguimiento de las trayectorias matrimoniales de las/os transgresores de la ley en un corpus documental diverso, como también la destreza narrativa y la imaginación de la autora para reconstruir sus historias abriendo nuevos caminos desde los cuales explorar el pasado. Finalmente, resulta importante explicitar que Bjerg nos sumerge como lectores/as en la intimidad de las historias conyugales haciéndonos revivir fragmentos de las vidas de sus protagonistas y nos interpela logrando, como plantea Ivan Jablonka, que a partir de nuestras propias experiencias establezcamos un vínculo entre el reconocimiento de las emociones en el otro y el hecho de sentirlas uno/a mismo/a. 
